\title{
LEGISLAÇÕES DE COMBATE À INTIMIDAÇÃO SISTEMÁTICA: ANÁLISE DE TEXTOS NORMATIVOS DO SUL DO BRASIL E DO PROGRAMA DE COMBATE À INTIMIDAÇÃO SISTEMÁTICA
}

LEGISLATION OF COMBATING SYSTEMIC INTIMIDATION: ANAL YSIS OF NORMATIVE TEXTS OF THE SOUTH OF BRAZIL AND THE PROGRAM OF COMBATING SYSTEMIC INTIMIDATION

\footnotetext{
${ }^{1}$ Pós-Doutorando em Democracia e Direitos Humanos pelo Centro de Direitos Humanos da Faculdade de Direito da Universidade de Coimbra/Portugal. Doutor em Direito Constitucional pela Pontifícia Universidade Católica, de São Paulo/SP. Mestre em Teoria do Estado pelo Centro Universitário "Eurípides Soares da Rocha", de Marília/SP. Professor do Mestrado em Direito do Centro Universitário "Eurípides Soares da Rocha", de Marília/SP. Autor, organizador e participante de inúmeras obras jurídicas. Palestrante no Brasil e no exterior. Advogado e consultor jurídico. Email: prof.rafaeldelazari@ hotmail.com

2 Graduado em Direito pela Fundação Educacional do Município de Assis - FEMA. Membro do Grupo de Pesquisa REI (Relações Institucionais) - Todos os lados do art. $2^{\circ}$ da Constituição Federal, cadastrado no diretório acadêmico de pesquisa do CNPQ. Advogado e consultor jurídico. Email: razabonijr@gmail.com
} 


\section{RESUMO}

O presente trabalho, de cunho hipotético-dedutivo, aborda todas as concepções do problema social nomeado pelo legislador contemporâneo como Intimidação. Sistemática, ou seja, "Bullying", conceituando este fenômeno e evidenciando sua ocorrência diante dos principais estudos efetuados dentro do território nacional. Aborda legislações nacionais acerca deste assunto, contemplando, de forma especial, a nova lei de combate à intimidação sistemática, demonstrando todos seus aspectos, com base no texto normativo, bem como seus possíveis efeitos e impactos.

Palavras-chave: Bullying. Violência. Intimidação Sistemática.

\section{ABSTRACT}

This hypothetical-deductive paper deals with all conceptions of the social problem named by the contemporary legislator as Intimidation. Systematics, that is, "Bullying", conceptualizing this phenomenon and evidencing its occurrence in front of the main studies carried out within the national territory. It addresses national legislation on this subject, especially contemplating the new law to combat systematic intimidation, showing all its aspects, based on the normative text, as well its possible effects and impacts.

Keywords: Bullying. Violence. Systematic Intimidation.

\section{INTRODUÇÃO}

O presente estudo tem como objetivo abordar e delimitar a intimidação sistemática, compreendida pelo fenômeno Bullying, utilizando para isto conceitos e a análise legislativa das principais leis vigentes nos estados do sul do Brasil.

Abordaremos também a nova legislação nacional acerca deste fenômeno e buscaremos evidenciar este problema social por meio de pesquisas realizadas em âmbito nacional, as quais demonstram a alta quantidade de violências praticadas em ambientes escolares.

Como princípio, ressalta-se que Bullying se trata de um termo de origem inglesa, o qual procura cognominar todas as várias espécies de intimidação, violência e agressões físicas e psicológicas que são praticadas por uma ou mais pessoas em desfavor de quem, aparentemente, encontra-se em condição de subalternidade.

No Brasil, a prática do Bullying não é recente, porém a regulamentação nacional surgiu apenas com a Lei $n^{\circ} 13.185 / 2015$, a qual entrou em vigor na data de 07 de fevereiro de 2016 e instituiu o Programa de Combate ao Bullying, ou como o legislador transladou para a língua portuguesa como o Programa de Combate à "Intimidação Sistemática". 


\section{CONCEITO DE “BULLYING”}

Apesar das diversas dificuldades encontradas em delimitar um conceito específico para o fenômeno Bullying, Cleo Fante, especialista em Bullying, leciona que:

Bullying é uma palavra inglesa, sem tradução em nossa língua. Bully pode ser traduzido como valentão, tirano, brigão. Os valentões da escola elegem como alvos colegas que apresentam dificuldade de defesa. Colocam apelidos constrangedores, intimidam, isolam, chantageiam, rejeitam, difamam, zoam, humilham, batem, perseguem. ${ }^{3}$

Ainda na procura de uma definição ideal para o fenômeno Bullying, vale ressaltar os ensinamentos de Alessandro Constantini, os quais dizem que:

Trata-se de um comportamento ligado à agressividade física, verbal ou psicológica. É uma ação de transgressão individual ou de grupo, que é exercida de maneira continuada, por parte de um indivíduo ou de um grupo de jovens definidos como intimidadores nos confrontos com uma vítima predestinada. ${ }^{4}$

No que se refere às ações realizadas por meio do Bullying, temos que são verdadeiros atos preconcebidos, ameaças e violências, que por sua vez são constantemente impostas a indivíduos vulneráveis e incapazes de se defenderem, o que os levam à condição de sujeição, sofrimento, angústia, isolamento e marginalização.

Em plano contínuo, considerando que este fenômeno ocorre na maioria das vezes em âmbito escolar e que o presente trabalho retratará o Bullying dentro das entidades de ensino, Diogo Dreyer expõe:

Todos os dias, alunos no mundo todo sofrem com um tipo de violência que vem mascarada na forma de "brincadeira". Estudos recentes revelam que esse comportamento, que até bem pouco tempo era conside-

\footnotetext{
${ }^{3}$ FANTE, Cleo; PEDRA, José Augusto. Bullying escolar: perguntas e respostas. Porto Alegre: Artmed, 2008, p. 132.

${ }^{4}$ COSTANTINI, Alessandro. Bullying: como combatê-lo? Prevenir e enfrentar a violência entre jovens. São Paulo: Itália Nova, 2004.
} 
rado inofensivo e que recebe o nome de Bullying, pode acarretar sérias conseqüências ao desenvolvimento psíquico dos alunos, gerando desde queda na auto-estima até, em casos mais extremos, o suicídio e outras tragédias. ${ }^{5}$

Nesse sentido, para uma ideal definição de violência, a qual pode ser dada de muitos modos, cabe ressaltar a lição de Michaud, que diz:

Há violência quando, em uma situação de interação, um ou vários atores agem de maneira direta ou indireta, maciça ou esparsa, causando danos a uma ou mais pessoas em graus variáveis, seja em sua integridade física, em suas posses ou em suas participações simbólicas e culturais. ${ }^{6}$

O fenômeno Bullying encontra-se subdividido em duas espécies, sendo elas divididas em Bullying direto, o qual é realizado por meio de agressões físicas e humilhações como empurrões, socos, chutes, no qual se atinge de maneira imediata a vítima; e Bullying indireto, o qual é realizado por meio de intimidação psicológica, suscitando o isolamento da vítima, por meios de calúnias, injúrias, difamações, pilhérias e outros meios de atemorizamento.

Destaca-se que o Bullying, em sua forma indireta, encontra grande dificuldade de percepção dos pais, responsáveis e educadores, já que não causa lesões aparentes. Neste sentido, mostra-se necessária a implantação de profissionais (psicólogos e assistentes sociais) em todas as unidades de ensino, a fim de delimitar as ocorrências, combatê-las e tratar as vítimas e agressores.

Farrinngton revela que o Bullying é uma "opressão repetida, de natureza física ou pisíquica, de uma pessoa com menos poder, por outra com mais poder". Prosseguindo seu pensamento, definiu elementos centrais para o reconhecimento deste fenômeno, os quais compreendem: 1) Prática de agressão física, verbal ou psciológica (intimidação); 2) O agressor é mais poderoso ou, pelo menos, assim é visto pela vítima; 3) Há a intenção de causar medo e/ou dor à vítima; 4) A agressão não é provo-

5 DREYER, Diogo. A brincadeira que não tem graça. Página 1. Disponível em: <http://www.educacional.com.br/reportagens/Bullying/>. Acessado em 22 de maio de 2016.

${ }^{6}$ MICHAUD, Yves. A violência. São Paulo: Atica, 1989. 
cada pela vítima; 5) As agressões são repetidas e 6) Os agressores alcançam o resultado desejado. ${ }^{7}$

Neste sentido, podemos concluir que ainda há duas características subjetivas para este fenômeno, as quais são: a satisfação do agressor ao impor sofrimento e a sensação da vítima de estar sendo oprimida. ${ }^{8}$

Além do fenômeno chamado Bullying, tivemos, com o avanço da tecnologia, a criação e o crescimento do CyberBullying, o qual é tratado como:

(...) uso da tecnologia da informação e comunicação (e-mails, telefones celulares, mensagens por pagers ou celulares, fotos digitais, sites pessoais difamatórios, ações difamatórias online) como recurso para a adoção de comportamentos deliberados, repetidos e hostis, de um indivíduo ou grupo, que pretende causar danos a outro(s). ${ }^{9}$

Ressalta-se que com o avanço da tecnologia, além da criação e da evolução do CyberBullying, obtivemos também o crescimento da violência, gerado pela exposição diária de programas e notícias televisivas e da rede mundial de computadores, que exteriorizam sentimentos de hostilidade, ferocidade, agressividade, impetuosidade, repassando, por sua vez, para crianças e adolescentes, as quais passam a entender como "normais" tais sentimentos.

\section{ESTUDOS NACIONAIS ACERCA DO FENÔMENO BULLYING.}

Aprofundando a análise acerca do ambiente escolar, como muito bem preceituado por Guilherme Domingos de Luca e Fernanda Milina de Carvalho Stança:

\footnotetext{
${ }^{7}$ FARRINGTON, D.P. Understangind and preventing Bullying. In: TONNY, M; Morris, N. (eds.) Crime and Justice. Chicago: University of Chicago Press, v. 17, p. 381-458, 1993.

${ }^{8}$ RIGBY, Ken. What is Bullying. Defining Bullying: a new look at na old concept, 2006. Disponível em: <http://www.education.unisa.edu.au/"Bullying"/.> . Acesso em 22 de maio de 2016.

${ }^{9}$ LOPES NETO, Aramis. A. Bullying - comportamento agressivo entre estudantes. Jornal de Pediatria (Rio de Janeiro). 2005, p. 166.
} 
Dentro desse cenário conflituoso onde deveria imperar o ensino, bons modos e costumes, além dos valores éticos e morais, acaba-se gerando conflitos que muitas vezes nem a filosofia, psicologia ou qualquer outra área do saber, em especial o Direito, é capaz de entender. ${ }^{10}$

Nessa senda, preceituam:

As relações escolares devem ser pautadas de respeito mútuo, por meio de atitudes que levassem à harmonia entre as pessoas (...) os índices de violência e demais estatísticas comprovam que tais abusos têmse tornado cada vez mais comum num local que em tese, deveria ser pautado da ética, dos bons costumes e da moral. ${ }^{11}$

Diversos estudos realizados apontam os altos índices de ocorrência do fenômeno Bullying como forma de violência em ambiente escolar, dentre os quais, vale ressaltar, "in verbis", o estudo realizado pela Associação Brasileira Multiprofissional de Proteção à Infância e à Adolescência, a qual expõe que:

(...) foi realizada com alunos de escolas de Ensino Fundamental do Rio de Janeiro, apresenta dados como o número de crianças e adolescentes que já foram vítimas de alguma modalidade de Bullying, que inclui, além das condutas descritas anteriormente, discriminação, difamação e isolamento. O objetivo do estudo é ensinar e debater com professores, pais e alunos formas de evitar que essas situações aconteçam. ${ }^{12}$

\footnotetext{
${ }^{10}$ LUCA, Guilherme Domingos de; STANÇA, Fernanda Molina de Carvalho. Violência no ambiente educacional e o papel pacificador do direito. Revista Espaço Acadêmico, Maringá, v. 173, p.63-74, out. 2015. Mensal, p. 72.

${ }^{11}$ LUCA, Guilherme Domingos de; STANÇA, Fernanda Molina de Carvalho. Violência no ambiente educacional e o papel pacificador do direito. Revista Espaço Acadêmico, Maringá, v. 173, p.63-74, out. 2015. Mensal, p. 67/68

12 DREYER, Diogo. A brincadeira que não tem graça. Página 1. Disponível em: <http://www.educacional.com.br/reportagens/Bullying/>. Acessado em 22 de maio de 2016.
} 
O estudo envolvendo 5.500 alunos, sendo esses da quinta à oitava série do ensino fundamental, apresentou, em seus dados iniciais, que:

(...) 40,5\% dos alunos admitiram estar diretamente envolvidos em atos de Bullying, sendo 16,9\% como alvos, $12,7 \%$ como autores e $10,9 \%$ ora como alvos, ora como autores; - $60,2 \%$ dos alunos afirmaram que o Bullying ocorre mais freqüentemente dentro das salas de aula; $\bullet 80 \%$ dos estudantes manifestaram sentimentos contrários aos atos de Bullying, como medo, pena, tristeza, etc. $\bullet 41,6 \%$ dos que admitiram ser alvos de Bullying disseram não ter solicitado ajuda aos colegas, professores ou família; • entre aqueles que pediram auxílio para reduzir ou cessar seu sofrimento, o objetivo só foi atingido em 23,7\% dos casos; $69,3 \%$ dos jovens admitiram não saber as razões que levam à ocorrência de Bullying ou acreditam tratar-se de uma forma de brincadeira; - entre os alunos autores de Bullying, 51,8\% afirmaram que não receberam nenhum tipo de orientação ou advertência quanto à incorreção de seus atos. ${ }^{13}$

Em sua avaliação final, após trabalho realizado em menos de um ano, a Associação Brasileira Multiprofissional de Proteção à Infância e à Adolescência detectou satisfatórias alterações:

(...) $79,9 \%$ dos alunos admitem saber o que é Bullying; • redução de $6,6 \%$ de alunos alvos; • redução de $12,3 \%$ de alunos autores de Bullying; $\bullet$ a indicação da sala de aula como local de maior incidência de atos de Bullying caiu de $60,2 \%$ para $39,3 \%$, representando uma queda de $24,7 \%$; $\bullet$ o número de alunos que admitia gostar de ver o colega sofrer Bullying reduziu-se em $46,1 \%$; • entre os alunos alvos que buscaram ajuda, o sucesso das intervenções para a redução ou cessação do Bullying teve um crescimento de 75,9\%; • o desconhecimento sobre o entendimento das razões que levam à prática de Bullying reduziu-se em $49,1 \%$; • aqueles que admitiram

\footnotetext{
${ }^{13}$ LOPES NETO, Aramis. A. Bullying - comportamento agressivo entre estudantes. Jornal de Pediatria (Rio de Janeiro). 2005.
} 
o Bullying como um ato de maldade passou de 4,4\% para $25,2 \%$ das respostas, representando um aumento de $472,7 \%$; • o número de alunos autores de Bullying que admitiu ter recebido orientações e advertências quanto à incorreção de seus atos passou de $45,6 \%$ para $68 \%$, representando um crescimento de $33,4 \% .{ }^{14}$

A Comissão criada pela $\mathrm{OAB} / \mathrm{SC}$, chamada de $\mathrm{OAB}$ Vai à Escola, também realizou estudos com as escolas da grande Florianópolis$\mathrm{SC}$, que apontou que:

(...) quase a totalidade dos alunos de oito escolas públicas da Grande Florianópolis convive com Bullying, drogas e violência doméstica, que há pouca participação dos pais na vida escolar dos filhos e que falta uma política pública em prol dos alunos. O perfil resultou de questionário realizado com 680 alunos e 97 professores de 11 escolas de Florianópolis, Biguaçu, Palhoça e São José, aplicado durante palestras da comissão nas escolas. ${ }^{15}$

Acerca dos resultados alcançados pelo estudo da Comissão da $\mathrm{OAB} / \mathrm{SC}$, em bases estatísticas, tem-se que:

A pesquisa revelou que $82 \%$ dos alunos convivem com Bullying e que grande parte já foi ou ainda é vítima da agressão. Em $52 \%$ dos casos a atitude é tomada pelos colegas, em $24 \%$ na comunidade, $21 \%$ na família e $11 \%$ pelos professores. Os principais motivadores da agressão apontados pelos alunos, na comunidade escolar, foram: físicos $(41 \%)$, sexuais

\footnotetext{
${ }^{14}$ LOPES NETO, Aramis. A. Bullying - comportamento agressivo entre estudantes. Jornal de Pediatria (Rio de Janeiro). 2005.

$15 \mathrm{OAB} / \mathrm{SC}$. Comissão OAB Vai à Escola. Disponível em: <http://www1.oabsc.org.br/noticias/oabsc-traca-perfil-escolas-publicas-grande-florianopolis/8595>. Acessado em $23 \mathrm{de}$ maio de 2016.
} 
(30\%), culturais $(13 \%)$, religiosos (11\%), familiares e intelectuais (8\%), e econômicos e étnicos $(5 \%) .{ }^{16}$

Deste modo, resta evidenciado que a ocorrência deste fenômeno se encontra inserido e encalacrado dentro do cotidiano escolar, porém, como demonstrado pela Associação Brasileira Multiprofissional de Proteção à Infância e à Adolescência, podemos diminuí-los, desde que com apoio dos profissionais da educação, pais ou responsáveis e com o devido tratamento de combate às intimidações.

\section{PROGRAMA DE COMBATE AO BULLYING DO ESTADO DE SANTA CATARINA.}

Como uma das primeiras leis vigentes tratando do tema $\mathrm{Bul}$ lying, nasce em 2009, o Programa de Combate ao Bullying, de ação interdisciplinar e de participação comunitária nas escolas públicas e privadas do Estado de Santa Catarina, por meio da lei no 14.651/2009.

Na busca de um combate efetivo nos ambientes escolares, o legislador Catarinense, traçou conceitos normativos para o Bullying, os quais se compreendiam como atitudes agressivas, intencionais e repetitivas, adotadas por um indivíduo (bully) ou grupo de indivíduos contra outro(s), sem motivação evidente, causando dor, angústia e sofrimento e, executadas em uma relação desigual de poder, o que possibilita a vitimização.

De modo simplório, porém até então praticamente inédito, o legislador trouxe, no bojo do artigo $2^{\circ}$ da lei supracitada, meios pelos quais se evidenciam o Bullying, como insultos pessoais, apelidos, ataques físicos, grafites, ameaças e pilhérias.

Em seu artigo terceiro, classificou ainda o Bullying por ações práticas, divididas em:

I - verbal: apelidar, xingar, insultar; II - moral: difamar, disseminar rumores, caluniar; III - sexual: assediar, induzir e/ou abusar; IV - psicológico: ignorar,

\footnotetext{
$16 \mathrm{OAB} / \mathrm{SC}$. Comissão OAB Vai à Escola. Disponível em: <http://www1.oabsc.org.br/noticias/oabsc-traca-perfil-escolas-publicas-grande-florianopolis/8595>. Acessado em $23 \mathrm{de}$ maio de 2016.
} 
excluir, perseguir, amedrontar, aterrorizar, intimidar, dominar, tiranizar, chantagear e manipular; V - material: destroçar, estragar, furtar, roubar os pertences; VI - físico: empurrar, socar, chutar, beliscar, bater; e VII - virtual: divulgar imagens, criar comunidades, enviar mensagens, invadir a privacidade. ${ }^{17}$

Além dos objetivos do programa, de forma correta, a fim de solucionar o problema e tratar os danos, a norma apresentou a possibilidade de encaminhar vítimas e agressores aos serviços de assistência médica, social, psicológica e jurídica, que poderão ser oferecidos por meio de parcerias e convênios.

Por fim, vale ressaltar que recentemente, semeado pelos grandes índices de Bullying, surge também no Estado de Santa Catarina, mais especificamente na capital de Florianópolis, a lei 16.441/2015, que instituiu o mês de março como o mês de combate ao Bullying escolar.

\section{COMBATE DA PRÁTICA DE “BULL YING” DO ESTADO DO RIO GRANDE DO SUL.}

Em 2010, um ano após o programa sugerido pelo Estado de Santa Catarina, surge o combate da prática de "Bullying" por instituições de ensino e de educação infantil, públicas ou privadas, com ou sem fins lucrativos.

No mesmo esteio da Lei Catarinense, a Lei do Rio Grande do Sul lança um conceito mais amplo, o qual fora disposto na lei 13.474/2010. Este é apresentado como a prática de qualquer ato de violência física ou psicológica, intencional e repetitiva, entre pares, que ocorra sem motivação evidente, praticada por um indivíduo ou grupo de indivíduos, contra uma ou mais pessoas, com o objetivo de intimidar, agredir fisicamente, isolar, humilhar, ou ambos, causando dano emocional e/ou físico à vítima, em uma relação de desequilíbrio de poder entre as partes envolvidas.

O artigo $1^{\circ}$ da Lei 13.474/2010 traz, de modo praticamente idêntico, o artigo $3^{\circ}$ da Lei Catarinense alusiva acima, porém acentuando que o envio de mensagens, fotos ou vídeos por meio de computador, celular ou assemelhado, bem como sua postagem em "blogs" ou "sites", cujo

\footnotetext{
${ }^{17}$ SANTA CATARINA. Programa de Combate ao Bullying, de ação interdisciplinar e de participação comunitária nas escolas públicas e privadas do Estado de Santa Catarina. Lei nº 14.651/2009.
} 
conteúdo resulte em exposição física e/ou psicológica a outrem, também seriam conhecidos como CyberBullying.

Os objetivos traçados pelo programa compreenderam, de forma objetiva, a iniciativa e intenção de:

I - reduzir a prática de violência dentro e fora das instituições de que trata esta Lei e melhorar o desempenho escolar; II - promover a cidadania, a capacidade empática e o respeito aos demais; III - disseminar conhecimento sobre o fenômeno "Bullying" nos meios de comunicação e nas instituições de que trata esta Lei, entre os responsáveis legais pelas crianças e adolescentes nelas matriculados; IV - identificar concretamente, em cada instituição de que trata esta Lei, a incidência e a natureza das práticas de "Bullying"; V - desenvolver planos locais para a prevenção e o combate às práticas de "Bullying" nas instituições de que trata esta Lei; VI - capacitar os docentes e as equipes pedagógicas para o diagnóstico do "Bullying" e para o desenvolvimento de abordagens específicas de caráter preventivo; VII - orientar as vítimas de "Bullying" e seus familiares, oferecendo-lhes os necessários apoios técnico e psicológico, de modo a garantir a recuperação da autoestima das vítimas e a minimização dos eventuais prejuízos em seu desenvolvimento escolar; VIII - orientar os agressores e seus familiares, a partir de levantamentos específicos, caso a caso, sobre os valores, as condições e as experiências prévias, dentro e fora das instituições de que trata esta Lei, correlacionadas à prática do "Bullying", de modo a conscientizá-los a respeito das consequências de seus atos e a garantir o compromisso dos agressores com um convívio respeitoso e solidário com seus pares; IX - evitar tanto quanto possível a punição dos agressores, privilegiando mecanismos alternativos como, por exemplo, os "círculos restaurativos", a fim de promover sua efetiva responsabilização e mudança de comportamento; $\mathrm{X}$ - envolver as famílias no processo de percepção, acompanhamento e formulação de soluções 
concretas; e XI - incluir a política "antiBullying" adequada ao regimento de cada instituição. ${ }^{18}$

Por fim, o texto normativo, como forma de incentivo ao combate do Bullying, acentuou a realização de palestras e debates, procurando com isto a adequada orientação de pais, alunos e educadores, sendo que as despesas decorrentes da execução desta Lei seriam por conta de dotações orçamentárias próprias, suplementadas se necessário.

\section{LEIS PARANAENSES ACERCA DO BULLYING.}

No mesmo ano de 2010, originou-se na cidade de Curitiba, capital do estado do Paraná, a Lei Municipal 13.632/2010, que dispõe sobre a política "antiBullying" nas instituições de ensino do município de Curitiba.

No esteio do artigo $2^{\circ}$, o legislado municipal delimitou conceito para o Bullying, que se compreende como:

Qualquer prática de violência física ou psicológica, intencional e repetitiva, entre pares, que ocorra sem motivação evidente, praticada por um indivíduo ou grupo de indivíduos, contra uma ou mais pessoas, com o objetivo de intimidar, agredir fisicamente, isolar, humilhar, ou ambos, causando dano emocional e/ou físico à vítima, em uma relação de desequilíbrio de poder entre as partes envolvidas. ${ }^{19}$

Em quadro de ações que caracterizam o fenômeno Bullying, a legislação municipal trouxe, em seu artigo $2^{\circ}, \S 1^{\circ}$, de forma taxativa, os meios pelos quais o Bullying pode ser compreendido, como, in verbis, ameaças e agressões verbais e/ou físicas, submissão a outrem de condição humilhante e constrangedora, furto, roubo, vandalismo e destruição de bens alheios, extorsões forçadas, insultos, apelidos, comentários xenofóbicos e racistas bem como isolamento proposital de vítimas.

\footnotetext{
${ }^{18}$ RIO GRANDE DO SUL. Combate da prática de "Bullying" por instituições de ensino e de educação infantil, públicas ou privadas, com ou sem fins lucrativos. Lei nº 13.474/2010.

${ }^{19}$ CURITIBA. Política "antiBullying" nas instituições de ensino do município de Curitiba. Lei $\mathrm{n}^{\circ}$ 13.632/2010 de 18 de novembro de 2010
} 
Com o aspecto tecnológico em alta, a lei impôs que a postagem e o envio de mensagens, fotos ou vídeos, por meio eletrônico, que resulte em exposição física e psicológica de crianças e adolescentes, sejam considerados cyberBullying.

Sob a égide do artigo $3^{\circ}$, a Lei "antiBullying" instituiu como principais objetivos:

I - reduzir a prática de violência dentro e fora das instituições de que trata esta Lei e melhorar o desempenho escolar; II - promover a cidadania, a capacidade empática e o respeito aos demais; III - disseminar conhecimento sobre o fenômeno "Bullying" nos meio de comunicação e nas instituições de que trata esta Lei, entre os responsáveis legais pelas crianças e adolescentes nela matriculados; IV - identificar concretamente, em cada instituição de que trata esta Lei, a incidência e a natureza das práticas de "Bullying"; V - desenvolver planos locais para a prevenção e o combate às práticas de "Bullying" nas instituições de que trata esta Lei; VI - capacitar os docentes e as equipes pedagógicas para o diagnóstico do "Bullying" e para o desenvolvimento de abordagens específicas de caráter preventivo; VII - orientar as vítimas de "Bullying" e seus familiares, oferecendo-lhes os necessários apoios técnico e psicológico, de modo a garantir a recuperação da autoestima das vítimas e a minimização dos eventuais prejuízos em seu desenvolvimento escolar; VIII - orientar os agressores e seus familiares, a partir de levantamentos específicos, caso a caso, sobre os valores, as condições e as experiências prévias - dentro e fora das instituições de que trata esta Lei - correlacionadas à prática do "Bullying", de modo a conscientizálos a respeito das consequências de seus atos e a garantir o compromisso dos agressores com um convívio respeitoso e solidário com seus pares; IX - evitar tanto quanto possível a punição dos agressores, privilegiando mecanismos alternativos como, por exemplo, os "círculos restaurativos", a fim de promover sua efetiva responsabilização e mudança de comportamento; $\mathrm{X}$ - envolver as famílias no processo de percepção, acompanhamento e formulação de 
soluções concretas; e XI - incluir no regimento a política "antiBullying" adequada ao âmbito de cada instituição. ${ }^{20}$

Por fim, insta observar que, em seu artigo $4^{\circ}$, a Lei impôs às escolas municipais o dever de manterem registradas todas as ocorrências de Bullying.

Em caráter estadual, influenciada pela lei municipal curitibana, surge em 2012 a Lei Estadual no 17.335/2012, que instituiu o Programa de Combate ao Bullying, de ação interdisciplinar e de participação comunitária, nas Escolas Públicas e Privadas do Estado do Paraná.

Com estrutura semelhante, porém não idêntica, a lei trouxe, em seu texto normativo, um novo conceito para Bullying. Cabe ressaltar que apresentou também as ações que o caracterizam, os objetivos do programa implantado e, de forma inaudita, classificações pelas quais o Bullying se concretiza.

Com efeito, no que consiste ao conceito, a norma estadual trouxe em seu artigo $1^{\circ}, \S$ único, dispositivo que considera prática de $\mathrm{Bul}$ lying:

Atitudes de violência física ou psicológica, intencionais e repetitivas, que ocorrem sem motivação evidente, praticadas por um indivíduo (bully) ou grupos de indivíduos, contra uma ou mais pessoas, com o objetivo de intimidá-la ou agredi-la, causando dor e angústia à vítima, em uma relação de desequilíbrio de poder entre as partes envolvidas. ${ }^{21}$

No que se refere às ações praticadas por crianças e adolescentes em ambiente escolar, o Bullying se faz por meio de violências como:

I - insultos pessoais; II - comentários pejorativos; III - ataques físicos; IV - grafitagens depreciativas; V -

\footnotetext{
${ }^{20}$ CURITIBA. Política "antiBullying” nas instituições de ensino do município de Curitiba. Lei ${ }^{\circ}$ 13.632/2010 de 18 de novembro de 2010

${ }^{21}$ PARANÁ. Programa de Combate ao Bullying, de ação interdisciplinar e de participação comunitária, nas Escolas Públicas e Privadas do Estado do Paraná. Lei n 17.335/2012 de 10 de Outubro de 2012.
} 
expressões ameaçadoras e preconceituosas; VI - isolamento social; VII - ameaças; VIII - pilhérias. $^{22}$

Previsto pela primeira vez em forma de legislação, o artigo $3^{\circ}$ da Lei estadual positiva a classificação dos casos de Bullying, divididos por:

I - sexual: assediar, induzir e/ou abusar; II - exclusão social: ignorar, isolar e excluir; II - exclusão social: ignorar, isolar e excluir; III - psicológica: perseguir, amedrontar, aterrorizar, intimidar, dominar, infernizar, tiranizar, chantagear e manipular; IV - verbal: apelidar, xingar, insultar; V - moral: difamar, disseminar rumores, caluniar; VI - material: destroçar, estragar, furtar e ou roubar os pertences; VII - físico: empurrar, socar, chutar, beliscar, bater; VIII - virtual: divulgar e ou enviar imagens, criar comunidades, invadindo a privacidade. ${ }^{23}$

Como forma de objetivos traçados pelo legislador estadual, a regra do artigo $5^{\circ}$ traz de forma contundente e aperfeiçoada, em vista da lei curitibana, dezesseis desígnios, quais são:

I - prevenir e combater a prática de Bullying nas escolas; II - capacitar docentes e equipe pedagógica para a implementação das ações de discussão, prevenção, orientação e solução do problema; III - incluir, no Regime Escolar, após ampla discussão no Conselho de Escola, regras normativas contra o Bullying; IV - esclarecer sobre os aspectos éticos e legais que envolvem o Bullying; V - observar, analisar e identificar eventuais praticantes e vítimas de Bullying nas escolas; VI - discernir, de forma clara e objetiva, o que é brincadeira e o que é Bullying; VII desenvolver campanhas educativas, informativas e

\footnotetext{
${ }^{22}$ PARANÁ. Programa de Combate ao Bullying, de ação interdisciplinar e de participação comunitária, nas Escolas Públicas e Privadas do Estado do Paraná. Lei nº 17.335/2012 de 10 de Outubro de 2012.

${ }^{23}$ PARANÁ. Programa de Combate ao Bullying, de ação interdisciplinar e de participação comunitária, nas Escolas Públicas e Privadas do Estado do Paraná. Lei nº 17.335/2012 de 10 de Outubro de 2012.
} 
de conscientização com a utilização de cartazes e de recursos de áudio e audiovisual; VIII - valorizar as individualidades, canalizando as diferenças para a melhoria da autoestima dos estudantes; IX - integrar a comunidade, as organizações da sociedade, as políticas setoriais públicas e os meios de comunicação nas ações interdisciplinares de combate ao Bullying; $\mathrm{X}$ - coibir atos de agressão, discriminação, humilhação e qualquer outro comportamento de intimidação, constrangimento ou violência; XI - realizar debates e reflexos a respeito do assunto, com ensinamentos que visem à convivência harmônica na Escola e na comunidade; XII - promover um ambiente escolar seguro e sadio, incentivando a tolerância e o respeito mútuo; XIII - propor dinâmicas de integração entre alunos, professores, demais profissionais da educação e da comunidade; XIV - estimular a amizade, a solidariedade, a cooperação e o companheirismo no ambiente escolar. XV - orientar pais e familiares sobre como proceder diante da prática de Bullying; XVI - auxiliar vítimas e agressores, orientando-os e encaminhando-os para a rede de serviços sociais, sempre que necessário. ${ }^{24}$

Por fim, a lei ainda preceitua a elaboração de plano de ações, por parte da instituição de ensino, para a concretização dos objetivos e implementação das medidas previstas no programa (art. $6^{\circ}$ ); a possibilidade de encaminhamento de vítimas e agressores a serviços de assistência médica, psicológica, social e/ou jurídica (art. $8^{\circ}$ ) e também a possibilidade de criação de órgão público específico para este particular (art. $9^{\circ}$ ).

\section{ANÁLISE DO PROGRAMA DE COMBATE À INTIMIDAÇÃO SISTEMÁTICA.}

Influenciada pela criação das Leis estaduais, tais como as Leis criadas pelos estados do sul, bem como apelo popular de participantes em

\footnotetext{
${ }^{24}$ PARANÁ. Programa de Combate ao Bullying, de ação interdisciplinar e de participação comunitária, nas Escolas Públicas e Privadas do Estado do Paraná. Lei no 17.335/2012 de 10 de Outubro de 2012 .
} 
audiência pública realizada perante a Comissão de Constituição e Justiça e de Cidadania (CCJ), nasce, com sete anos de tramitação, originada em junho de 2009, como projeto de lei $\mathrm{n}^{\mathrm{o}} 5369 / 2009$, e posteriormente transformada em Lei Ordinária 13.185/2015, o Programa de Combate à Intimidação Sistemática, consistente na primeira norma de âmbito nacional que dispõe sobre este fenômeno Bullying, ou como o legislador preferiu chamar como Intimidação Sistemática.

Apresenta por sua vez, em seu artigo $1^{\circ}, \S 1^{\circ}$, conceito enunciado agora pelo legislador nacional, dispondo que todo ato de violência física ou psicológica, intencional e repetitivo que ocorre sem motivação evidente, praticado por indivíduo ou grupo, contra uma ou mais pessoas, com o objetivo de intimidá-la ou agredi-la, causando dor e angústia à vítima, em uma relação de desequilíbrio de poder entre as partes envolvidas.

No que diz a respeito às ações violentas praticadas nas escolas, a lei determina que sejam consideradas como intimidações sistemáticas:

I - ataques físicos; II - insultos pessoais; III - comentários sistemáticos e apelidos pejorativos; IV - ameaças por quaisquer meios; V - grafites depreciativos; VI - expressões preconceituosas; VII - isolamento social consciente e premeditado; VIII - pilhérias. $^{25}$

De forma insólita na legislação pátria, o legislador reconheceu a existência da intimidação sistemática na rede mundial de computadores (cyberBullying), a qual ocorre quando se usarem os instrumentos que lhe são próprios para depreciar, incitar a violência, adulterar fotos e dados pessoais com o intuito de criar meios de constrangimento psicossocial.

A lei trouxe também, a exemplo da lei curitibana e paranaense, de forma taxativa, todos os meios pelos quais este fenômeno se perfaz, os quais estão dispostos nos incisos do artigo $3^{\circ}$ desta forma:

Art. 3: A intimidação sistemática (Bullying) pode ser classificada, conforme as ações praticadas, como: I - verbal: insultar, xingar e apelidar pejorativamente; II - moral: difamar, caluniar, disseminar rumores; III - sexual: assediar, induzir e/ou abusar; IV - soci-

\footnotetext{
${ }^{25}$ BRASIL. Programa de Combate à Intimidação Sistemática (Bullying). Lei $n^{\circ} 13.185$ de 6 de novembro de 2015.
} 
al: ignorar, isolar e excluir; $\mathrm{V}$ - psicológica: perseguir, amedrontar, aterrorizar, intimidar, dominar, manipular, chantagear e infernizar; VI - físico: socar, chutar, bater; VII - material: furtar, roubar, destruir pertences de outrem; VIII - virtual: depreciar, enviar mensagens intrusivas da intimidade, enviar ou adulterar fotos e dados pessoais que resultem em sofrimento ou com o intuito de criar meios de constrangimento psicológico e social. ${ }^{26}$

$\mathrm{Na}$ égide do artigo $4^{\circ}$, surgem os principais objetivos do programa, que são, em primeiros traços, combater e prevenir o Bullying, capacitando os profissionais da área da educação, a fim de orientá-los a solucionar os problemas caso a caso originados pelo Bullying.

A Lei ainda programa a intenção de campanhas de educação, conscientização e informação, com práticas de conduta e orientação de pais, familiares e responsáveis diante da identificação de vítimas e agressores, disponibilizando assistência psicológica, social e jurídica tanto à vítima quanto ao agressor.

Integra os meios de comunicação de massa com as escolas e a sociedade, como meio de identificação e conscientização do problema e forma de preveni-lo e combatê-lo.

E por fim, dispõe que, evitará, tanto quanto possível, a punição dos agressores, privilegiando mecanismos e instrumentos alternativos que promovam a efetiva responsabilização e mudança de comportamento hostil.

Além dos objetivos e da tradução da palavra inglesa para "intimidação sistemática", a Lei de Combate ao Bullying estabelece que será dever do estabelecimento de ensino, dos clubes e das agremiações recreativas, assegurar medidas de conscientização, prevenção, diagnose e combate à violência e à intimidação sistemática e bem como serão produzidos e publicados relatórios bimestrais das ocorrências de intimidação sistemática nos Estados e Municípios para planejamento das ações.

\section{CONCLUSÕES}

\footnotetext{
${ }^{26}$ BRASIL.Programa de Combate à Intimidação Sistemática (Bullying). Lei ${ }^{\circ} 13.185$ de 6 de novembro de 2015.
} 
A violência, em todas suas derivações, causa danos, muitas vezes irreparáveis. Quando esta se encontra ligada ao Bullying, principalmente na fase infanto-juvenil, pode gerar graves consequências psicológicas e sociais às vítimas, de modo que se não debeladas, pode se tornar um dano insanável.

Sustentáculos, amparo e apoio são medidas necessárias a fim de reprimir condutas agressivas, pois um sentimento de inferioridade pode comprometer o desenvolvimento de uma pessoa, trazendo sentimentos de insegurança, carência, frustração, dificuldades, pouca auto-estima, sentimento de incompetência etc.

Aparentemente, tanto as Leis dos estados do sul do Brasil, quanto o Programa Brasileiro de Combate à Intimidação Sistemática, isto é "Bullying", cumprem bem o papel de traçar os primeiros passos para a prevenção deste problema social em âmbito nacional, facilitando o diagnóstico do que é o Bullying, como este se perfaz e como as autoridades e os responsáveis devem agir em face deste.

Nessa ótica, é possível de se perceber que a inserção de textos normativos no cotidiano educacional, mostra-se como medida essencial para o combate aos altos índices de violência existentes.

Porém, tais leis e principalmente o novo Programa de Combate à Intimidação Sistemática não serão a solução do Bullying nos ambientes escolares.

Encontramo-nos ainda em um enorme lapso temporal para, quem sabe um dia, com a ampliação e criação de outros meios de combate, extinguir, ou, ao menos diminuir a um plano satisfatório a ocorrência deste problema social, em que essas pequenas ocorrências não passarão de fatos ínfimos e esparsos perante a sociedade, bem como, na vida das vítimas, não afetando assim de forma direta a existência, o desenvolvimento e a dignidade destas.

A paz, a exemplo dos objetivos traçados pelas legislações "antiBullying", pode ser auferida; para isto tornar-se claro a necessidade de utilizar o caminho do respeito mútuo, devendo ser tolerada toda diferença, proporcionando assim, um ambiente escolar digno e saudável para as crianças e os adolescentes, futuros da Nação.

\section{REFERÊNCIAS BIBLIOGRÁFICAS}


ABRAMOVAY, Miriam (Org.). Cotidiano das escolas: entre violências. Brasília: Unesco, 2006.

BRASIL. Constituição (1988). Constituição da República Federativa do Brasil. Brasília: Senado, 1988.

Programa de Combate à Intimidação Sistemática (Bullying). Lei $\mathrm{n}^{\circ}$ 13.185 de 6 de novembro de 2015.

COSTANTINI, Alessandro. Bullying: como combatê-lo? Prevenir e enfrentar a violência entre jovens. São Paulo: Itália Nova, 2004.

CURITIBA. Política "antiBullying" nas instituições de ensino do município de Curitiba. Lei $n^{\circ}$ 13.632/2010 de 18 de novembro de 2010.

DREYER, Diogo. A brincadeira que não tem graça. Página 1. Disponível em: $<$ http://www.educacional.com.br/reportagens/Bullying/>. Acessado em $22 \mathrm{de}$ maio de 2016.

FANTE, Cleo; PEDRA, José Augusto. Bullying escolar: perguntas e respostas. Porto Alegre: Artmed, 2008.

FARRINGTON, D.P. Understangind and preventing Bullying. In: TONNY, M; Morris, N. (eds.) Crime and Justice. Chicago: University of Chicago Press, v. 17, p. 381-458, 1993.

. Developmental Criminology and Risk-Focused Prevention. In: The Oxford Handbook of Criminology. Oxford: Oxfor University Press, 2002.

LOPES NETO, Aramis. A. Bullying - comportamento agressivo entre estudantes. Jornal de Pediatria (Rio de Janeiro). 2005.

LUCA, Guilherme Domingos de; STANÇA, Fernanda Molina de Carvalho. Violência no ambiente educacional e o papel pacificador do direito. Revista Espaço Acadêmico, Maringá, v. 173, p.63-74, out. 2015. Mensal.

MICHAUD, Yves. A violência. São Paulo: Atica, 1989

MORRISON, Brenda. Bullying Escolar e Justiça Restaurativa: Compreensão Teórica do Papel do Respeito, Orgulho e Vergonha.Justiça para o Século 21. Instituindo Práticas Restaurativas, p. 4. Disponível em: <http://www.justica21.org.br/j21.php?id=356\&pg=0\#.V0c26PkrLIU> Acesso em: 22 de maio de 2016.

NUNES, Taiana da Silva. O professor e o Bullying escolar: significados e estratégias de ação. 2011. 145 f. Tese (mestrado) - Curso de Psicologia, Universidade Federal da Bahia, Salvador, 2011, p.80. Disponível em: <http://www.pospsi.ufba.br/Taiana_Nunes.pdf $>$. Acessado em: 23 de maio de 2016.

NASCIMENTO, Grasiele Augusta Ferreira; ALKIMIN, Maria Aparecida. Violência na escola: O Bullying na relação aluno-professor e a responsabilidade jurídica, 2010, p.1 Disponível em http://www.publicadireito.com.br/conpedi/manaus/arquivos/anais/fortaleza/3 776.pdf >. Acesso em: 22 de maio de 2016.

. Direitos Humanos na sociedade contemporânea : O Bullying como ato infracional.

em: 
<http://www.lo.unisal.br/direito/semidi/publicacoes/livro5/Grasiele\%20Aug us-

ta\%20Ferreira\%20Nascimento\%20e\%20Maria\%20Aparecida\%20Alkimin.p df $>$. Acessado em 23 de maio de 2016.

$\mathrm{OAB} / \mathrm{SC}$. Comissão OAB Vai à Escola. Disponível em: <http://www1.oabsc.org.br/noticias/oabsc-traca-perfil-escolas-publicas-grandeflorianopolis/8595>. Acessado em 23 de maio de 2016.

PARANÁ. Programa de Combate ao Bullying, de ação interdisciplinar e de participação comunitária, nas Escolas Públicas e Privadas do Estado do Paraná. Lei $\mathrm{n}^{\circ}$ 17.335/2012 de 10 de Outubro de 2012.

RIGBY, Ken. What is Bullying. Defining Bullying: a new look at na old concept, 2006. Disponível em: <http://www.education.unisa.edu.au/"Bullying"/.> . Acesso em 22 de maio de 2016.

RIO GRANDE DO SUL. Combate da prática de "Bullying" por instituições de ensino e de educação infantil, públicas ou privadas, com ou sem fins lucrativos. Lei $\mathrm{n}^{\circ}$ 13.474/2010.

TIERNO, Barnabé. Ajudar os filhos em seus problemas. 1. ed. São Paulo: Paulinas, 1996.

SANTA CATARINA. Programa de Combate ao Bullying, de ação interdisciplinar e de participação comunitária nas escolas públicas e privadas do Estado de Santa Catarina. Lei ${ }^{\circ}$ 14.651/2009.

SARLET, Ingo Wolfgang. Dignidade da pessoa humana e direitos fundamentais na Constituição Federal de 1988. 5 ed. rev. e atual. Porto Alegre: Livraria do Advogado, 2007.

SPOSITO, Marília Pontes. (2001). Um breve balanço da pesquisa sobre violência escolar no Brasil. Educação e Pesquisa, São Paulo. 